\title{
Análisis semiótico greimasiano de la Venezuela de abril de 2002. Una aproximación explicativa del Efecto CNN
}

\section{A Greimasian Semiotic Analysis of Venezuela in April 2002. An Approach to the CNN Effect}

\author{
Max Römer Pieretti, profesor de Comunicación Social. Universidad Católica Andrés Bello (Venezuela)
}

Recibido: 1-XII-2008 - Aceptado: 8-II-2009

Resumen:

El conflicto político venezolano del año 2002, ha sido bastante difícil de comprender por parte del mundo internacional debido a la deformación de la información tanto dentro de Venezuela, como fuera de ella, ya que muchos intereses de los medios de comunicación social, y de algunos periodistas, han desdibujado esta realidad, además de las posiciones obvias del mundo político. La desinformación de cara a los venezolanos sufrió graves silencios que dieron supremacía -si se quiere- pérdida de soberanía informativa, hacia el público venezolano, lo que generó un vacío informativo que no fue sufrido por la comunidad internacional. El trabajo se fundamenta en un análisis semiótico, desde la isotopía de Greimas en que se muestra la irrupción del llamado Efecto CNN en la sociedad venezolana a raíz del silencio de los medios de comunicación venezolanos el día 13 de abril de 2002. Igualmente, si colateralmente se observa, podría ser una aproximación a la creación de un escenario de comprensión de la realidad venezolana de los días 11 al 13 de abril de 2002.

Palabras clave:

Efecto CNN, Venezuela, medio de comunicación, Greimas, isotopía, cuadrado semiótico.

\section{Abstract:}

The Venezuelan political conflict of 2002 has been quite difficult to understand from the international world because of the distortion of information both within Venezuela and beyond, as many interests of the media and some journalists, have blurred this fact, besides the obvious positions of the political world. Disinformation facing Venezuelans suffered heavy silences that gave supremacy, if you want information, loss of sovereignty, to the Venezuelan public, creating an information vacuum that was not suffered by the international community. The work is based on a semiotic analysis, since the isotopy of Greimas which shows the emergence of the so-called CNN Effect in Venezuelan society as a result of the silence of the Venezuelan media the day April 13 2002. Similarly, if collateral is observed, it might be an approach to creating a scenario for understanding the reality in Venezuela on 11th to 13th April 2002.

Keywords:

CNN Effect, Venezuela, media, Greimas, isotopy, semiotic square. 


\section{Introducción}

Abril del año 2002, fue para Venezuela uno de esos momentos aciagos en los que se confundieron roles institucionales, se desbidujaron funciones y sobre todo, se puso en tela de juicio a los medios de comunicación social venezolanos, ergo, al periodismo.

Fue a la vez, un momento de confusión política en el que la ciudadanía afecta a la oposición o al oficialismo se volcó a las calles buscando defender sus intereses. Abril de 2002 fue un espacio en el que se demostraron fuerzas antagónicas, se mostraron caras diversas de un día para el otro. Lealtades que no fueron sino traiciones, apoyos políticos que se volcaron a irrealidades, aparentes ejercicios democráticos que se revistieron de extrema derecha, en fin, un momento que quedó para la historia contemporánea venezolana, pleno de equivocaciones, que terminó padeciendo el ciudadano venezolano.

Las decisiones políticas ejercidas a través de los órganos policiales o desde la Fuerza Armada, generaron muertes y heridas en venezolanos, distorsionaron los roles de estas instituciones defensoras de la seguridad, a la vez que generaron caos en la población y desconfianza hacia las instituciones políticas, los medios de comunicación y en general, todo el aparato empresarial, económico y social que hace vida en un país.

La opinión pública internacional tuvo una visión muy particular de los acontecimientos, una visión desde la mirada de CNN y las cadenas internacionales de información, realidad muy lejana a la vivida por los venezolanos, quienes aterrorizados trataban de saber qué ocurría en sus ciudades y calles, estas plenas de estupor y violencia, de confusión de roles.

Fue un momento en el que el pueblo opositor marchó hasta el Palacio de Miraflores pidiendo la renuncia del presidente de la República, Hugo Rafael Chávez Frías, mientras el pueblo que respaldaba al presidente daba soporte a su mandato a las puertas de palacio. Fue la antesala a una guerra civil que duró un día y que a la postre restituyó el poder a Chávez, luego de una toma de poder que se consideró golpe de Estado.

Además de los elementos políticos e institucionales de esos días, de la población que se vio afectada, entre los días 11 al 13 de abril, se produjeron hechos inéditos en el mundo comunicativo venezolano, ¡los medios de comunicación social venezolanos dejaron de informar! Esta condición posibilitó, desde nuestro punto de vista, la irrupción del llamado Efecto $C N N$, que en pocas palabras es la pérdida de la soberanía informativa de un país y la irrupción de una visión de tono internacional de los acontecimientos. Los venezolanos sólo tenían información por parte de esta cadena y sólo aquellos que tenían acceso a sistemas satelitales de televisión.

El Efecto CNN tiene el riesgo de mostrar desde la óptica de las políticas de comunicación de cada cadena internacional, los sucesos que en un país ocurren. Huelga escribir que las distorsiones informativas están a 
la orden de los periodistas de las cadenas internacionales. Desde nuestro punto de vista, se pierde el equilibrio isotómico del discurso en manos de muchos actores informativos.

Para este trabajo hemos escogido una figura semiótica muy conocida, el cuadrado semiótico greimasiano. La escogencia de este cuadrado y no las sucesivas investigaciones semióticas que se han hecho a partir del modelo, es la plataforma que usaremos, toda vez que queremos demostrar la pérdida del concepto isotópico tal y como lo planteara en su momento Greimas. Recordemos que Greimas proponía que todo discurso se fundaba en su opuesto. Esta condición hace que exista el equilibrio isotómico que Greimas y los griegos proponen. Este modelo con cuarenta años cumplidos, se basa en las isomorfías que conforman la bautizada isotopía, es decir, elementos que en contraste con otro, generan antagonismos. Por ser ampliamente manejada, dejaremos los aspectos metodológicos de lado y nos concentraremos en mostrar los resultados finales luego de los muchos cuadrados semióticos que surgieron de estos acontecimientos.

Bajo el concepto isotópico enfrentaremos a la oposición y al oficialismo venezolanos, y veremos cómo el día 13 de abril la desinformación y los vacíos de poder político generaron la irrupción del Efecto CNN.

Para alcanzar el objetivo de este trabajo, se revisaron el modelo greimasiano que da pie al cuadrado semiótico a través de la isotopía, los elementos que definen al Efecto CNN, llevaremos los acontecimientos de abril a una operacionalización semiótica, volcaremos los sintagmas en cuadrados semióticos, observaremos cómo se puede perder el concepto isotópico y concluiremos acerca del momento en el que surge el Efecto $C N N$. Podrá ver el lector una pincelada del aspecto metodológico, más lo relevante del estudio es la demostración de cómo en el plano de la semiótica puede surgir el llamado Efecto CNN al romperse la estructura discursiva isotópica y desdibujarse el plano discursivo de dos hablantes a un tercero que no pertenece a la conversación (las cadenas internacionales de noticias).

Como hallazgo colateral, veremos cómo el modelo greimasiano no es útil para todo tipo de análisis textual precisamente por la pérdida de estos elementos isotópicos que venimos apuntando al menos en el caso de estudio.

\section{Marco teórico}

Greimas (1976) asume que si en un sintagma se producen al menos dos figuras sémicas, allí se puede establecer una isotopía; este tipo de enunciados, plantea la posibilidad de someter los sintagmas a pruebas isotópicas, y es en esta capacidad descriptiva de los sintagmas que se privilegia la dimensión conocida, comparable y conmutable de las unidades sintácticas. Las unidades no sintácticas, no dejan de ser unidades de 
contenido, razón por la cual nos podríamos preguntar si la investigación semántica no es capaz de “aportar otros elementos de apreciación que permitan el reconocimiento de continuidades isótopas” (p. 110).

Para efectos de nuestro estudio, contemplamos en este marco teórico una serie de definiciones que consideramos fundamentales. Si bien es cierto que no sacian exhaustivamente todo el método propuesto por Greimas (1976), los elementos que contemplamos aquí, conformarán la base estructural que se verá en el marco metodológico.

Así, iniciamos definiendo como paralexema al ámbito del metalenguaje que pertenece a todo sintagma:

- $\quad$ Sintagma: es una unidad de significado.

- $\quad$ Semema: es una unidad de contenido independiente de su cobertura lexemática y de su contorno contextual" (p. 130)

- Clasema: es la "linearidad (linealidad) semántica relativamente homogénea del discurso" (p. 120)

- La expansión “contiene en sí la negación de dicha jerarquía (unidad de significación) debido a que las unidades de comunicación de dimensiones diferentes pueden (,) al mismo tiempo (,) ser reconocidas como equivalentes" (p. 111). Así, A y B pueden considerarse equivalentes toda vez que para la existencia significativa de A se supone la existencia significativa de un elemento B, lo que se traduce en una isotopía propia de cada uno de los elementos relacionados.

- Condensación y denominación: "si reconocemos en la expansión uno de los modos del funcionamiento metalingüístico del discurso, tiene, como corolario la condensación, que debe ser entendida como una especie de descodificación comprensiva de los mensajes en expansión” (p. 114)

- $\quad$ Así, podemos entender para efectos de este trabajo, los conceptos elementales que se hacen necesarios para la conformación de los sintagmas que generarían una isotopía, la cual entendemos como el balance necesario entre dos o más elementos pertenecientes a una misma categoría, que la conforman, que la definen.

Seguidores y detractores de Greimas desarrollaron aún más el término de isotopía. Así, extendieron el término y generaron nuevas tipologías de isotopías. Nos permitimos colocar al pie una traducción de un texto de Nöth (1995) que explica estas posiciones relativas al concepto isotópico de Greimas ${ }^{1}$.

\footnotetext{
1 A partir del modelo inicial de la concatenación contextual sémica, la teoría de la isotopía fue progresivamente expandiéndose para abarcar a las recurrencias y otros niveles textuales. En adición a las isotopías semánticas, Greimas y Courtés (1979), distinguen las isotopías gramáticas, actoriales, parciales y globales. Los roles isotópicos, condensación y expansión, se sumarían después. En referencia
} 


\subsection{El manejo del cuadrado semiótico de Greimas}

Si consideramos que en el cuadrado semiótico de Greimas se puede comprender como un dinamismo que parte de S1 hacia S2 y tiene relación directa de contradicción -S1 con S1, quedando la relación como: las oposiciones constituyen ejes semánticos que representan dos tipos diferentes de lógica relacional. El primer tipo, contradicción (-S2_S2 y-S1_S1), es la relación que existe entre dos tipos de términos de categoría binaria. El segundo tipo, contrariedad (S1-S2), ya que los términos implican el contrario uno del otro. El tercer tipo, complementariedad (-S2_S1)

\subsection{El Efecto CNN}

El Efecto CNN, es la denominación que se dio en la última década del siglo XX a la aparente capacidad de los medios de comunicación internacionales, de los cuales esa cadena de noticias ha sido emblemática, para influir determinantemente en el curso de los conflictos internacionales y especialmente en la promoción y destitución de gobiernos en todo el mundo. La omnipresencia de la televisión ha sido tal que el hecho de que podamos contemplar las mismas imágenes de manera simultánea y en todo el mundo, ha modificado nuestra percepción de la realidad contemporánea y en ocasiones ha llevado a suponer que todo se resuelve en el contundente cernidor de los medios de alcance planetario (Trejo, 2003)

Por su parte, Robinson (2002, c. p. Trejo, 2003) plantea de una forma alterna, la existencia del Efecto CNN, como algo más mencionado que demostrado² . De allí, nuestro interés en contribuir a su definición y demostración.

El Efecto CNN es la tendencia de globalización de los discursos noticiosos que determina una forma de pensar, semióticamente hablando, de acuerdo al discurso globalizado y la tendencia que, la famosa cadena, condiciona en un momento específico como agenda mundial de información.

Sumando al concepto del Efecto CNN, podemos incluir en este trabajo la postura de Meysaan (2005), quien afirma que "la información en tiempo real se ha transformado paradójicamente en un espectáculo en que

a la expansión, la tipología de las isotopías se extiende hacia el concepto de la semiología isotópica, que abarca las iteratividades en términos exteroceptivos del mundo del conocimiento. Este concepto a su vez, se subdivide en isotopías temáticas y figurativas. La expansión del concepto de isotopía fue propuesta por Rastier (1972b), quien extendió sus tipologías de las isotopías desde el nivel del contenido hasta el nivel de la expresión lo que describe los recursos morfológicos y fonéticos (como por ejemplo ritmo y asonancia) como casos de isotopía. Eco (1984b), por su parte, propuso otro tipo de isotopías

3 El Efecto CNN ha sido más mencionado que demostrado. El resultado es una constante incertidumbre sobre el alcance y significado del Efecto CNN, tanto como persistencia de una injustificada y ampliamente extendida suposición de que los medios noticiosos tiene el poder de "mover" y "sacudir" a los gobiernos. 
la veracidad es algo accesorio. Debido al lugar central que ocupa en este sistema, la CNN se ha convertido en un instrumento de propaganda global”

Asumimos entonces, como una primera parte de la definición que nos interesa en este trabajo, que el "Efecto $C N N$ ”, aunque no es una teoría firmemente demostrada, es un fenómeno comunicativo que está en la palestra de las pautas informativas de los medios de comunicación social televisuales ${ }^{3}$.

Entonces, como una segunda parte de la definición relativa al Efecto CNN tendríamos el tema de la soberanía del telespectador, un individuo que se ilusiona políticamente hablando con la información que maneja, que considera que su manejo informativo es relativo a su capacidad de poseer información.

Es interesante destacar que los trabajos que conocemos acerca del Efecto $C N N$, plantean que la cadena de TV ocupa lugares importantes en el ámbito de la opinión de los líderes políticos de los países. Que la cadena es capaz de ubicar a cada uno de los sujetos entrevistados en un rol relativo al de amigo o enemigo de un proceso informativo o político (Meyssan, 2006; Langa, 2006; Treviño, 2005).

Esta capacidad que aparentemente tiene el Efecto CNN lleva a plantearnos el tercer elemento: la politización de la TV globalmente manejada.

En ese ámbito, considera Livingston (c. p. Treviño, 2005) que hay tres tipos de efectos para el terreno político con respecto a la información transmitida por cadenas informativas. Uno es acelerar los procesos de toma de decisiones; otro, inhibir posibles iniciativas en las políticas públicas; y por último, en el establecimiento de actores políticos capaces de definir la agenda mediática y, sobre todo, política.

Retomamos el tema de la agenda política. El Efecto CNN determina la agenda política, es decir, condiciona lo que los líderes políticos de un país, los temas que deben tomarse en cuenta, lo que "realmente" ocurre al estilo CNN.

Este efecto plantea, además la mirada que los políticos mundiales hacen a un acontecimiento cuando CNN se vuelca sobre una noticia y se traduce en esfuerzos diplomáticos (Neuman 1996, c. p. Langa, 2006)

Lo reflejado por CNN o las cadenas internacionales de noticias en un momento determinado se puede convertir, más que en la agenda noticiosa, en la agenda política de un país.

\footnotetext{
3 Pueblo se moviliza en función de informaciones que tiene y dicta al instante su voluntad a sus representantes. Se convierte en el soberano. El telespectador de la CNN se ve en medio de la Historia que se desarrolla ante sus ojos, es testigo directo de ella y tiene la ilusión de que puede modificarla (Centro de Medios Independientes de Puerto Rico, 2005)
} 
Esta condición ubica a los medios de comunicación de tono internacional en una posición de privilegio, de suprapoder político, de controladores de destinos, si lo vemos desde una óptica crítica. O visto desde una óptica totalmente liberal, como parte del juego que la economía de libre mercado propone.

De cualquier manera, ambas posiciones establecen para las cadenas de noticias internacionales la posibilidad de irrumpir en el espacio territorial de un país, de asumirse en un momento de crisis, como los abanderados de la soberanía de los países sobre la base del control noticioso.

Así, podemos concluir que son tres los ámbitos que el Efecto CNN propone:

- $\quad$ Es un fenómeno comunicativo de ámbito global;

- $\quad$ Plantea al telespectador como soberano de la información;

- $\quad$ Plantea la politización de las cadenas de TV a favor de procesos informativos de acuerdo a los intereses políticos de la propia cadena de TV;

Y, podríamos agregar que puede convertirse en el único informante de una condición socio-política en situaciones coyunturales especiales tal y como la que describimos en este trabajo.

\section{Marco histórico}

En este trabajo no pretendemos hacer una historia exhaustiva de la Venezuela de abril de 2002, por el contrario, nuestro interés es más bien utilizar la cronología que el diario El Universal publicó en sus primeras páginas los días 12, 13 y 15 de abril, ya que es de hacer notar que el día 14 de abril de 2002 no circuló este diario. Escogemos a El Universal por ser el único de los medios impresos venezolanos que destinó sus primeras páginas a reflejar los acontecimientos de ese fin de semana y que coinciden, luego del visionado completo -por parte del investigador- de las transmisiones de CNN cronológicamente. Por ser estos dos medios, El Universal y CNN, los que reflejan de modo más fehaciente los acontecimientos de ese abril en Venezuela.

Así, los acontecimientos que se verán reflejados en adelante, son los que el diario recoge. Para nuestra tranquilidad, contrastamos esta cronología con los materiales audiovisuales que transmitió la cadena norteamericana de noticias CNN durante el 11 y 12 de abril, ya que Globovisión (canal venezolano de 24 horas de noticias), quien nos proporcionó esta posibilidad de visionado no posee las transmisiones del día 13 de ese canal estadounidense. Por otro lado, esta cronología se ajusta muy bien al documental "La Revolución no será televisada” de las realizadoras irlandeses Kim Bartley y Donnacha O'Briain (2003). 
Como se ve, este no es un análisis de los medios, sino de los acontecimientos noticiosos recogidos por dos medios de comunicación que, una vez contrastados, funcionan a modo de expresión del discurso de los actores de los acontecimientos políticos y sociales.

Cronología de los acontecimientos del 11 al 13 de abril de 2002:

\section{El 11 de abril}

>Policía Metropolitana y partidarios del Gobierno se enfrentaron a tiros. > La Guardia Nacional reprimió a quienes pretendian llegar a las puertas de Miraflores. >Trabajadores de PDVSA marcharon en las ciudades donde opera la petrolera. >En Ciudad Bolivar los estudiantes de la UDO quemaron cauchos. >Anclados los feries en Puerto La Cruz y Margarita. >En Cumaná detuvieron a 24 estudiantes que protestaban. >Universitarios de Mérida provocaron disturbios. >En Valera marcharon cuatro mil personas. > La policía controló intentos de saqueos en Maracay. >Fedecámaras solicita la renuncia del Presidente. > La CTV contacta a militares disidentes. >Ejecutivo de PDVSA exigen revertir todas las medidas del Gobierno ara negociar. >CNNy Telemundo transmitieron todos los hechos en el exterior. >En el Zulia falla el suministro de algunas estaciones de gasolina. > Amuay está totalmente paralizada. > En la refinería de Puerto la Cruz se detuvo el despacho de gasolina. >Avanza la reactivación de El Palito. $>$ En Caracas los supermercados abrieron durante la mañana y se abarrotaron de compradores nerviosos. > La banca operó hasta el mediodía. >Anoche hubo una revuelta en Yare con saldo de 15 heridos. >Urgen donantes de sangre en los hospitales de Caracas (El Universal, primera página, 12 de abril de 2002).

A la vez, este medio señalaba en su titular que "Chávez renunció y se entregó a las cuatro de la madrugada" (El Universal, primera página, 12 de abril de 2002), y que "Pedro Carmona Estanca presidirá la junta de Gobierno de transición” (El Universal, primera página, 12 de abril de 2002).

Esta portada de la prensa, señala con detalle la cadena que arropó los acontecimientos de la marcha que se acercó hasta el Palacio de Miraflores, la solicitud de perdón por parte del comandante general del Ejército, General Efraín Vásquez Velasco, así como la salida del presidente Chávez del Palacio de Miraflores y cómo este fue despedido por sus ministros con las notas del Himno Nacional (El Universal, primera página, 12 de abril de 2002).

\section{El 12 de abril}

>Disuelta y allanada administrativamente la Asamblea. >Llamarán a elecciones legislativas antes de fin de año y ejecutivas en un lapso no mayor de 365 días. >Restablecido el nombre de República de Venezuela. >Facultado el presidente de transición para remover gobernadores y alcaldes. >Destituidos los miembros de todos 
los poderes públicos. >Anuladas las 49 leyes de la Habilitante. >Se mantiene el ordenamiento jurídico. >Diosdado Cabello dice que ni él ni Chávez han renunciado. >La hija de Chávez cuenta que su padre le dijo por teléfono que es un golpe. $>$ El fiscal y el defensor desconocen nuevo gobierno. $>$ Presidente del TSJ y contralor renunciaron. >Detenidos Rodríguez Chacín y Tarek William Saab. >Dávila regresó ayer al país. >Se desconoce paradero de varios exministros. $>$ EEUU elogia la prudencia de militares venezolanos. $>$ Bush dice que fue culpa de Chávez. >G-Río pide a la OEA que investigue las circunstancias del cambio en el país. >Lameda vuelve a presidir Pdvsa. >Restituida la anterior directiva de la petrolera. >Paralizan envíos de petróleo a Cuba. >Refinerías inician recuperación operativa. >Wall Street se muestra entusiasta ante los cambios. >Dólar cayó a Bs. 815. >Bolsa de Caracas sube 10.4\%. Bonos de la deuda suben 6,6\%. >Mercado petrolero estable. >Los servicios públicos restablecidos casi en su totalidad.>Líneas aéreas internacionales suspenden varios vuelos. >Canal 8 fuera del aire. >Calma y tranquilidad en la ciudad. >Vacío total en Alcaldía y Concejo Libertador. >Concejales de Sucre sesionaron sin J.V. Rabel Avalos, a quien le allanaron la casa. > Las víctimas de la jornada del $11^{a}$ totalizan 15 muertos y 350 heridos. >Detenidas cuatro personas en 12 allanamientos en Caracas. >Gobernador de Barinas, ausente, promete regresar. >Antonia Muñoz no renuncia y dide que es un golpe. >Gobernador de Bolívar pone su puesto a la orden. >Ronald Blanco, en Táchira, y Florencio Porras, en Mérida, sacados a la fuerza de sus respectivos palacios de gobierno. >Manifestaciones en contra en Maracay.>Gobernador de Falcón dispuesto a llamar a referendo (El Universal, primera página, 13 de abril de 2002)

Al igual que en la edición antes reseñada, El Universal rinde cuenta de los acontecimientos del día 12 de abril, al destacar "Instalado gobierno transitorio en Miraflores" (El Universal, primera página, 13 de abril de 2002), y de expresar el interinato de Pedro Carmona como presidente de Venezuela (El Universal, primera página, 13 de abril de 2002).

Igualmente, destaca al cuerpo ministerial que acompañó ese interinato.

El 13 de abril

>Saqueos y disturbios en diversos lugares de Caracas provocan 32 fallecidos. >Cofavic reporta 52 muertes desde el 11 de abril hasta ayer. >PM pide se investiguen sucesos del 11 de abril. >Decretan alerta en hospitales. >Supermercados solicitan protección de la GN. >Diosdado Cabello dice que pudiera haber cárcel para los insurrectos. $>$ Fedecámaras expresa que no quería el poder y aboga por la libertad de Carmona Estanca. $>$ Denuncian represión del interinato durante manifestaciones. >Evalúan reenganches en Pdvsa. >Trabajadores de la petrolera confiados en llegar a acuerdos. >Se restituyen las exportaciones de petróleo. > Regresan los gobernadores del oficialismo. >Televisoras fueron hostigadas por grupos de chavistas. >Saquearon comercios en el edificio del Colegio de Periodistas. > Los medios retornan a sus labores. > Policías de Baruta y Chacao dicen 
que detención de Rodríguez Chacín fue legal. >Bernal hace un llamado a la tranquilidad. >Catalán a favor de la restitución del hilo constitucional. >Rangel Avalos nunca abandonó el municipio. >Capriles y Salas Römer consideran necesario llamar a elecciones. >Peña prefiere a Chávez que a un golpe de Estado. >Saab considera que el interinato era fascista. >Parlamento intentará sesionar hoy. >J.V. Rangel considera que la oposición pierde terreno (El Universal, primera página, 15 de abril de 2002).

Luego de esta cronología de acontecimientos, El Universal también expresa en la primera página del día 15 de abril el retorno del poder del presidente Chávez, los saqueos en el área metropolitana, así como diferentes reacciones a los sucesos (El Universal, primera página, 15 de abril de 2002).

De la misma manera como hemos revisado los días 11 y 12, este 13 no será la excepción.

A simple vista, la diferencia fundamental de este día con los anteriores, es que no se puede observar con claridad las diferencias entre oposición y oficialismo, ya que se desdibuja el panorama político, se confunden los actores socio-políticos y se desconoce quien realmente detenta el poder.

Para el discurso oposicionista venezolano, CNN fue factor de perturbación en la credibilidad de la acción política emprendida en abril de 2002, cuando Harris Whitbeck y Otto Neustald transmitían desde Venezuela una posición de golpismo ante el mundo, cuando lo que ocurría-además de este visión acertada en el plano político- era una realidad de saqueos y perturbaciones sociales que distaban de esa actitud por parte del pueblo opositor, aunque no así de la dirigencia político-económica que tomó el poder por algunas horas, sin duda más cercana a los reporteros de CNN.

Para el discurso político oficialista, la transmisión de CNN y Radio Caracol de Colombia fue ocasión propicia para restaurar el poder político del presidente Chávez, y la oportunidad de que el presidente se comunicase a través de sus familiares con el mundo entero, dando pie a la sensación de golpismo que se observó en estos medios de cobertura internacional.

Creemos que la posición que mejor ilustra el proceso relativo a los errores cometidos por la prensa venezolana, y la intervención de la prensa extranjera en los acontecimientos de abril de 2002, lo resume el artículo de Ibsen Martínez (2002). En este artículo Martínez destaca la pobre actuación de los medios venezolanos, no sólo de los periodistas sino de los editores quienes decidieron censurar la información, aún la proveniente de medios internacionales. Si nos paseamos por la prensa de opinión de ambos bandos durante esos días, veremos cómo lo internacional puede ser destacado como favorable por parte del gobierno y cómo no lo fue por parte de la oposición. 
De hecho, lo primero que hace el presidente Hugo Chávez Frías al volver al poder fue enviar "un saludo especial a los medios de comunicación internacionales en primer lugar" (Baig, 2006) dando pie a que el pueblo comprendiera que la soberanía mediática estuvo en manos de las cadenas internacionales de noticias.

La información dividida entre opositora y oficial, si se quiere maniquea, estableció una distancia entre lo que se dijo de Venezuela en el mundo, lo que los políticos pretendían, y lo que los venezolanos desconocíamos de lo que estaba ocurriendo en las calles por un silencio mediático, sólo subsanado por las transmisiones de CNN y Radio Caracol de Colombia, a las cuales se pudo, durante un breve lapso de tiempo, antes que se cortara la señal, acceder por los servicios de suscripción de DirecTV.

\section{Objetivos de la investigación}

Objetivo general:

Analizar bajo la óptica del cuadrado semiótico de Greimas la situación político-cívica de los acontecimientos venezolanos del 11 al 13 de abril de 2002

Objetivos específicos:

Operacionalizar los acontecimientos políticos-cívicos bajo los parámetros greimasianos.

Contrastar los acontecimientos con su capacidad informativa de acuerdo a la matriz que arrojan los postulados del Efecto CNN y observar que la pérdida de la soberanía informativa se puede perder al existir desinformación nacional e irrumpir dicho efecto.

\section{Marco metodológico}

Este es un estudio de corte transversal, ex post facto, de investigación documental, semiótico.

Abarca los días 11 al 13 de abril de 2002 en Venezuela y no contempla reacciones posteriores al período estudiado aunque sí reconoce elementos previos a dicho período, por ser estos fundamentales para comprender las reacciones de alguno de los grupos políticos que se estudiarán.

Para poder estudiar los diferentes aspectos de ese período de la historia reciente venezolana, se usará la cronología presentada en las primeras páginas del diario "El Universal" contrastadas con estudios periodísticos y punto de vista de cineastas extranjeros. 
Esta cronología se considera texto a ser descompuesto y replanteado como sintagma que se usará como integrante de los distintos cuadrados semióticos.

En los cuadrados semióticos, se podrá evaluar la relación isotópica de los acontecimientos del período estudiado.

Greimas propone un método para alcanzar la isotopía del discurso, es decir, para que dos o más elementos tengan su antagónico, su definidor por oposición.

Sobre la base metodológica creada por Greimas, más la secuencia discursiva de los días 11 al 13 de abril de 2002, se presenta la matriz que servirá para la construcción de los cuadrados semióticos. Esta matriz incorpora los fenómenos descritos por el Efecto CNN cuando aplique alguno de esos elementos.

Así, los componentes de la matriz que se usará son:

- $\quad$ Efecto $C N N$

- Sema

- Lexema

- $\quad$ Paralexema

- $\quad$ Sintagma

- $\quad$ Expansión y definición

- Clasema

- Condensación y Denominación

- $\quad$ Semema

- $\quad$ Ocurrencia

De acuerdo al esquema que Greimas propone, A/está en relación (S) con/B, A sería la oposición; S el conflicto político nacional de Venezuela en abril de 2002; y, B el sector oficial. 
Para la relación entre A y B, tenemos que cada elemento propuesto en la matriz, definirá al sintagma que se vaciará en el cuadrado semiótico.

Greimas (1976) usa este esquema, como modo de articulación sémica con la fórmula:

Figura $n^{\circ} 1$. Esquema articulación sémica (tomado de Greimas, 1976: 41)

$$
\frac{\text { S (es la propiedad de) A }}{\text { (femineidad) (mujer) }}
$$

Y la aplicamos a los procesos propios de cada uno de los semas de este trabajo, tendríamos una estructura sémica semejante a esto:

Figura $n^{\circ} 2$. Esquema articulación sémica aplicado a la oposición venezolana (creación propia)

$\frac{\text { Se va (es propiedad de) pueblo opositor }}{\text { (lema) (grupo político y cívico opositor al gobierno de Chávez) }}$

Que, en oposición a la otra estructura sémica,

Figura $n^{\circ} 3$. Esquema articulación sémica aplicado a los seguidores del gobierno venezolano (Creación propia)

$$
\frac{\text { No pasarán (es propiedad de) pueblo a favor del gobierno }}{\text { (lema) (grupo político y cívico "chavista") }}
$$

Ambos lexemas, opuestos entre sí, nos permitirían crear la base del cuadrado semiótico greimasiano de la siguiente forma:

Grupo político y cívico opositor al gobierno de Chávez vs. Grupo político y cívico "chavista" 
Bajo ese esquema y considerando con Greimas que la "estructura es el modo de existencia de significación, caracterizado por la presencia de la relación articulada de dos semas" (42) y, que no pueden formularse lejos del lenguaje (42), la posibilidad de crear o recrear lo acontecido en abril de 2002 en Venezuela, se conforma por un gran primer cuadrado semiótico gestado en las calles de Caracas el día 11 de ese mes. Así:

Figura $n^{\circ} 4$. Cuadrado semiótico de Greimas (1976) con articulación sémica oposición y oficialismo (creación propia)

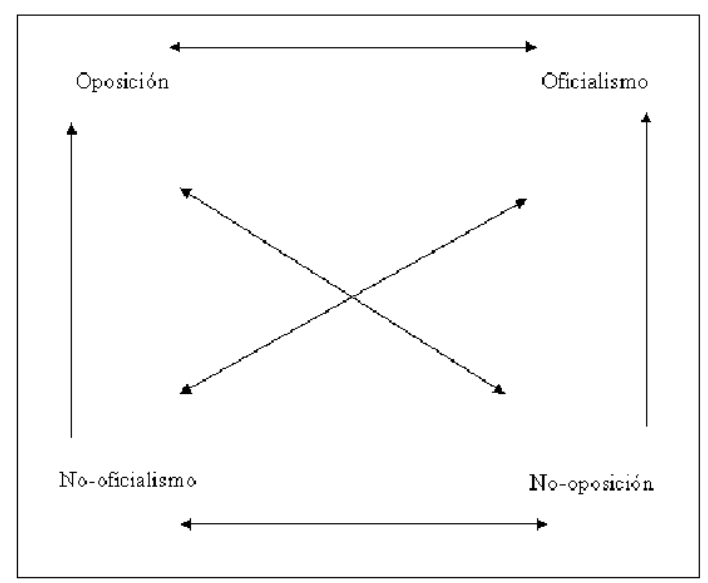

Como los conceptos son en sí mismos opuestos por estar dentro de dos semas políticos divergentes, constituyéndose en un lexema que evidentemente puede seguir toda la cadena greimasiana propia de la isotopía.

Posterior a ese procedimiento de clasificación de los acontecimientos de abril de 2002, de acuerdo a su cronología y, una vez convertidos en elementos mórficos para cada una de las partes del conflicto, se buscará crear una base de isomorfismos que nos permita establecer las isotopías propias del fenómeno político-cívico de esos días.

Consideramos que, oposición y gobierno oficial pueden ser equivalentes por contener en sí mismas la negación de sus jerarquías y son, a la vez, unidades de significación.

De esa forma, se pretende reagrupar los acontecimientos en cuadros semióticos -no expuestos en este trabajo mas sí sus conclusiones una a una-y evaluar la irrupción del Efecto CNN en el fenómeno político-cívico escogido. 
El Efecto CNN por su parte, que se desarrollará en la matriz, contendrá, si fuere el caso, alguno de los indicadores que se enuncian en la tabla de seguidas.

Tabla ${ }^{\circ} 1$. Efecto CNN, indicadores e ítems

\begin{tabular}{|l|c|c|}
\hline Efecto $C N N$ & Indicadores & Itemes \\
\hline & Determina la agenda política & \\
\hline & Acelera procesos de toma de decisiones & \\
\hline & Inhibe políticas públicas & $\begin{array}{c}\text { Inhibe posibilidades } \\
\text { comunicativas locales }\end{array}$ \\
\hline & $\begin{array}{c}\text { Fenómeno comunicativo } \\
\text { global }\end{array}$ & \\
\hline & $\begin{array}{c}\text { Plantea al teleespectador como } \\
\text { soberano de la información }\end{array}$ & \\
& $\begin{array}{c}\text { Plantea la politización de las cadenas } \\
\text { de acuerdo a los intereses políticos de } \\
\text { la propia cadena de TV }\end{array}$ & \\
\hline
\end{tabular}

Para efectos del análisis semiótico que vamos a desarrollar, vamos a mostrar la cronología de los acontecimientos contrapuesta en unas tablas que resumen, si puede usarse el término, en bloques diarios - por cada uno de los días estudiados- para cada uno de los actores políticos del país, es decir, oposición y oficialismo. Esta figura es determinante para la compresión temporal de los sucesos.

El 11 de abril

Tabla $n^{\circ} 2$. Semas opuestos del 11 de abril de 2002

\begin{tabular}{|l|l|}
\hline Oposición & Oficialismo (Gobierno de Chávez) \\
\hline $\begin{array}{l}\text { La marcha organizada se desvía hacia el Palacio } \\
\text { de Miraflores }\end{array}$ & $\begin{array}{l}\text { El Presidente de la República da un discurso a sus } \\
\text { seguidores en las puertas del Palacio de Miraflores }\end{array}$ \\
\hline En las proximidades del palacio, se inicia un tiroteo & $\begin{array}{l}\text { El gobierno intenta reprimir la marcha a través de } \\
\text { la Guardia Nacional }\end{array}$ \\
\hline
\end{tabular}




\begin{tabular}{|l|l|}
\hline $\begin{array}{l}\text { Los medios de comunicación tratan de informar } \\
\text { acerca de los acontecimientos de la ciudad }\end{array}$ & $\begin{array}{l}\text { El Presidente encadena a los medios de } \\
\text { comunicación con su discurso }\end{array}$ \\
\hline Fedecámaras solicita la renuncia del Presidente & Se informa que el Presidente renunció \\
\hline
\end{tabular}

El 12 de abril

Tabla $n^{\circ} 3$. Semas opuestos del 12 de abril de 2002

\begin{tabular}{|l|l|}
\hline Oposición & Oficialismo (Gobierno de Chávez) \\
\hline Allanados y disueltos los poderes & Prisionero el presidente Chávez \\
\hline Revestimiento de democracia & $\begin{array}{l}\text { Se presume golpe de Estado en esferas } \\
\text { internacionales }\end{array}$ \\
\hline Pedro Carmona es el presidente interino & Se desconoce el paradero de Chávez \\
\hline Derrocado Carmona Estanca & Diosdado Cabello presidente interino \\
\hline
\end{tabular}

\section{El 13 de abril}

Tabla ${ }^{\circ} 4$. Semas opuestos (no-opuestos) a causa de la revuelta social del 13 de abril de 2002.

Estos semas dan pie a la irrupción al Efecto $C N N$ al desdibujarse los actantes oposición y oficialismo y confundirse ambos en violencia callejera.

\begin{tabular}{|l|l|}
\hline Oposición & Oficialismo (Gobierno de Chávez) \\
\hline Son hostigadas las televisoras & $\begin{array}{l}\text { Venezolana de TV es el único canal que transmite } \\
\text { acerca de instituciones chapistas }\end{array}$ \\
\hline Saqueos a comercios & Muertos y heridos \\
\hline Agresiones a sedes diplomáticas & $\begin{array}{l}\text { Sensación de golpismo en el mundo, domina el } \\
\text { discurso de las cadenas internacionales de } \\
\text { noticias, se pierde la hegemonía y soberanía } \\
\text { de la información }\end{array}$ \\
\hline Diosdado Cabello - Presidente & Hugo Chávez - retoma el poder \\
\hline
\end{tabular}




\section{Resultados}

De seguidas, y con la base metodológica explicada arriba, llevaremos la relación de cada acontecimiento, tanto de la oposición como del oficialismo. La relación temporal será expresada bajo la óptica del día del suceso. Tan solo vamos a usar como muestra (por razones de espacio de publicación) uno de los sintagmas analizados. Esto con miras a dejar que las tablas de los cuadrados semióticos puedan explicarse por sí mismas y se ilustre adecuadamente el Efecto CNN.

Policía Metropolitana y partidarios del Gobierno se enfrentaron a tiros.

Tabla $n^{\circ} 5$. Ejemplo de la aplicación metodológica greimasiana

11 de abril: Policía Metropolitana y partidarios del Gobierno se enfrentaron a tiros

\begin{tabular}{|l|l|}
\hline Efecto CNN & Posible determinación de agenda política \\
\hline Sema & Policía \\
\hline Lexema & Opositora \\
\hline Paralexema & $\begin{array}{l}\text { Se sabe desde hace algún tiempo que la PM y el } \\
\text { gobierno están distanciados porque el segundo } \\
\text { pretende dominar al primero }\end{array}$ \\
\hline Sintagma & $\begin{array}{l}\text { Policía Metropolitana y partidarios del Gobierno } \\
\text { se enfrentaron a tiros }\end{array}$ \\
\hline Clasema & Poder judicial paralelo al gobierno \\
\hline Expansión y definición & Al ser opositora, su expansión es el oficialismo \\
\hline Condensación y Denominación & Rompe con lo aparentemente establecido \\
\hline Semema & $\begin{array}{l}\text { Policía Metropolitana (Policía de Caracas), la } \\
\text { cual es comandada por el Alcalde Mayor de la } \\
\text { Ciudad, rompe con los elementos establecidos } \\
\text { de obediencia al gobierno central }\end{array}$ \\
\hline Ocurrencia & $\begin{array}{l}\text { Desde un tiempo anterior al acontecimiento } \\
\text { citado }\end{array}$ \\
\hline
\end{tabular}


Aplicación del cuadrado semiótico de Greimas al 11 de abril

Análisis sobre la base del cuadrado semiótico del día 11 de abril: fase 1/3

La isotopía greimasiana tiene un fundamento isomórfico propio de las dos posiciones políticas del momento. En este cuadrado semiótico se plantea un claro enfrentamiento de fuerzas.

Si añadimos el componente informativo de las cadenas internacionales, tenemos no sólo el desarrollo de una agenda informativa propia de los acontecimientos previos, sino que la magnitud de la marcha opositora generó especial atención en estos medios de comunicación.

Figura $n^{\circ} 1.11$ de abril: 1/3 Aplicación del cuadrado semiótico de Greimas

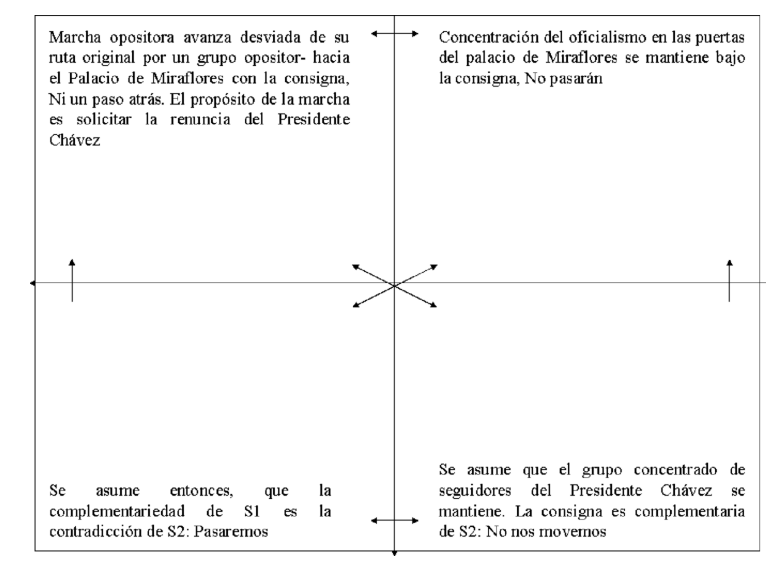

Análisis sobre la base del cuadrado semiótico del día 11 de abril: fase 2/3

La conflictividad producto de la movilización genera una obvia isotopía de tono político-civil. Las acciones de quienes detentan el poder se atrincheran en el manejo informativo, mientras los civiles protagonizan acciones conflictivas de calle. 
Figura n². 11 de abril: 2/3 Aplicación del cuadrado semiótico de Greimas

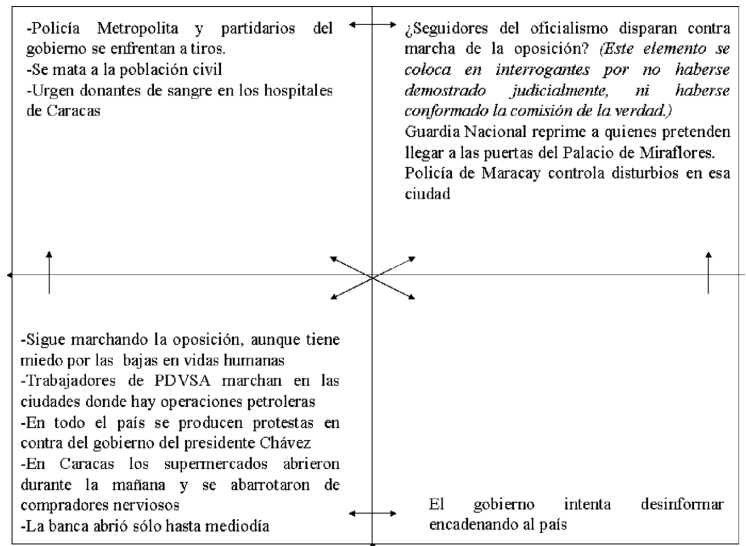

Análisis sobre la base del cuadrado semiótico del día 11 de abril: fase 3/3

La batalla sale del conflicto de calle y es llevada al plano informativo. El conflicto está ahora en el dominio de los medios de comunicación social. Quienes pretenden el poder quieren mantener la información a toda costa. Quien detenta el poder pretende también el manejo mediático.

La isotopía se mantiene sobre la base de la posición política esgrimida y sobre el manejo informativo de la coyuntura

Figura n³. 11 de abril: 3/3 Aplicación del cuadrado semiótico de Greimas

\begin{tabular}{|l|l|}
\hline $\begin{array}{l}\text { A algunos canales de TV la Guardia } \\
\text { Nacional les corta la señal. }\end{array}$ & $\begin{array}{l}\text { El gobierno nacional encadena la señal de } \\
\text { radio y TV mientras ocurren los hechos de } \\
\text { represión y violencia en las cercanías del } \\
\text { Palacio de Miraflores } \\
\text { En la cadena se observa un discurso que el } \\
\text { presidente Chávez hace frente a los } \\
\text { seguidores que están en las afueras del } \\
\text { palacio. }\end{array}$ \\
\hline$\uparrow$ & \\
\hline $\begin{array}{l}\text { Canales de TV transmiten con artilugios } \\
\text { ténicos } \\
\text { eNN y Telemundo transmiten los hechos } \\
\text { En el Zulior falla suministro de Estaciones } \\
\text { de gasolina. } \\
\text { Amuay está totalmente paralizada } \\
\text { En la refineria de Pto. La Cruz se detuvo } \\
\text { el despacho de gasolina }\end{array}$ & $\begin{array}{l}\text { Se genera relación informativa sólo por } \\
\text { parte del gobierno }\end{array}$ \\
\hline
\end{tabular}


Análisis sobre la base del cuadrado semiótico del día 12 de abril: fase 1/3

La conflictividad lleva a los actores de la oposición a exigir la renuncia del presidente Chávez y a disolver de forma dudosa a algunas instituciones del Estado.

La condición de "aparente" detención del poder por parte de la oposición, genera alianzas en organismos de seguridad del Estado.

La relación isotópica se mantiene desde el punto de vista de los actores del oficialismo y la oposición.

Si observamos el tema del interés informativo, la agenda noticiosa se mantiene con los ojos sobre Venezuela.

\section{Figura $\mathrm{n}^{\circ}$ 4. 12 de abril: 1/3 Aplicación del cuadrado semiótico de Greimas}

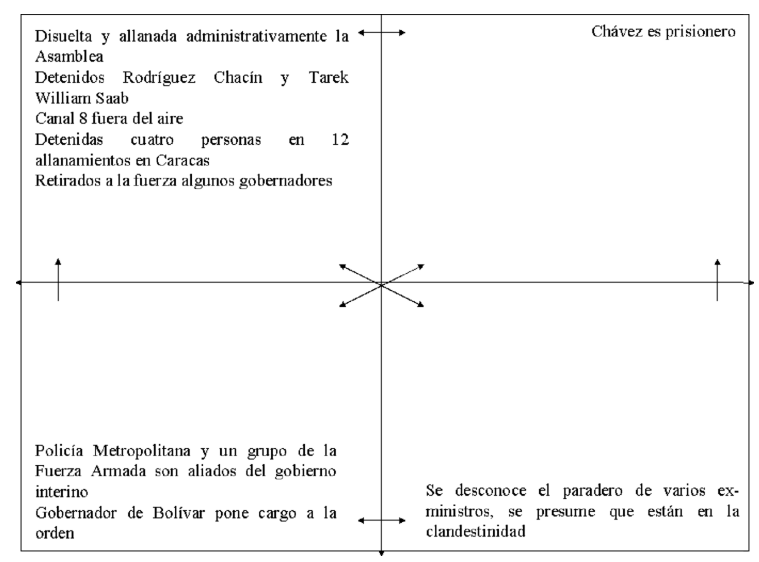

Análisis sobre la base del cuadrado semiótico del día12 de abril: fase 2/3

Las fuentes consultadas con posterioridad a los acontecimientos, en especial el libro de Meza y De La Fuente, plantean que el presidente Chávez no firmó la renuncia. En el ámbito informativo "en directo", lo manejado por los medios de comunicación social, esta información se creyó como verídica el día 12 de abril a las 4.00 am. El caso es que desde la presidencia de la República se vio por los medios de comunicación social la salida de Hugo Chávez Frías acompañado por personeros de la Iglesia Católica Venezolana. Esta condición ilustrativa de la salida del presidente del Palacio de Miraflores, hizo pensar, más allá de los anuncios formales de parte del general Lucas Rincón Gutiérrez, que el presidente se había entregado. 
El vacío de poder que se generó, dio pie a la formalización por parte de Fedecámaras de la candidatura de Pedro Carmona Estanga a la presidencia de transición.

Figura $n^{\circ} 5.12$ de abril: 2/3 Aplicación del cuadrado semiótico de Greimas

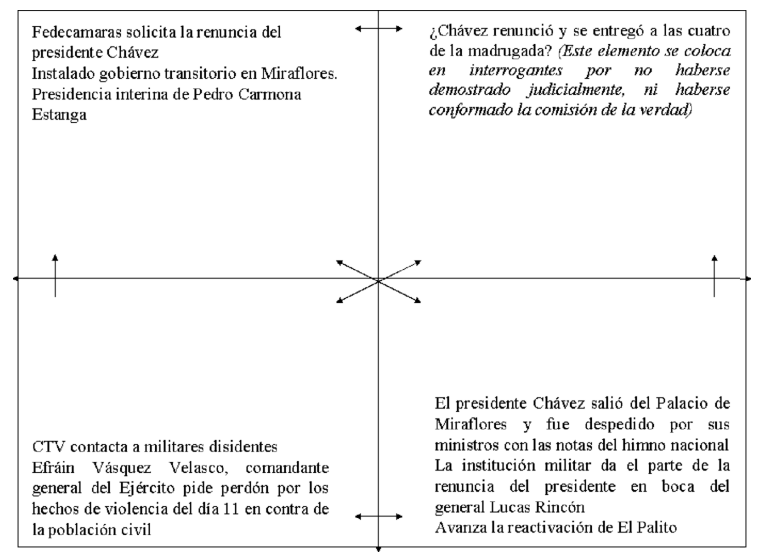

Análisis sobre la base del cuadrado semiótico del día 12 de abril: fase 3/3

El proceso isotópico se mantiene en este cuadrado. Cada uno de los cuadrantes establece la misma relación isomórfica que hemos desarrollado.

Es de hacer notar que el elemento que mantiene el conflicto proviene de información mediatizada: la hija de Hugo Chávez dice que se trata de un golpe de estado.

Esta condición establece una duda razonable entre quienes manejan la información desde las cadenas de noticias, y a la vez, genera una nueva agenda informativa que plantea inquietud entre quienes siguen a ambos bandos de la coyuntura política nacional, así como internacionales. 
Figura $\mathrm{n}^{\circ}$ 6. 12 de abril: 3/3 Aplicación del cuadrado semiótico de Greimas

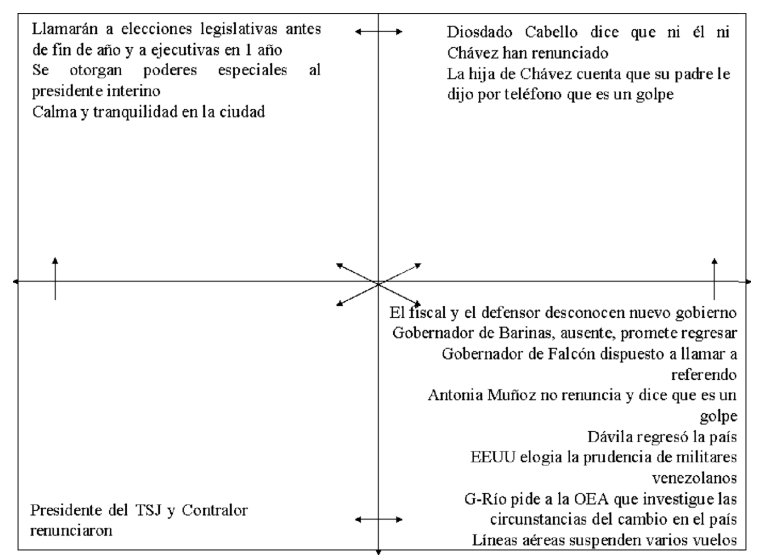

Aplicación del cuadrado semiótico de Greimas al 13 de abril

Análisis sobre la base del cuadrado semiótico del día 13 de abril: fase 1/3

En este cuadrado semiótico se puede observar que la isotopía se mantiene entre la oposición, que ahora tiene el poder político, y el oficialismo que misteriosamente ha desparecido del panorama político.

Esta ausencia del chavismo hace que se mantenga la presencia de ella como actor político, toda vez que se hace indispensable que la misma exista, aunque sea como referente.

En lo relativo a la información, el manejo se hace desde una óptica de satisfacción de las políticas comunicacionales de los medios. Es decir, aspectos de interés del mundo de los capitales. 
Figura $n^{\circ} 7.13$ de abril: 1/3 Aplicación del cuadrado semiótico de Greimas

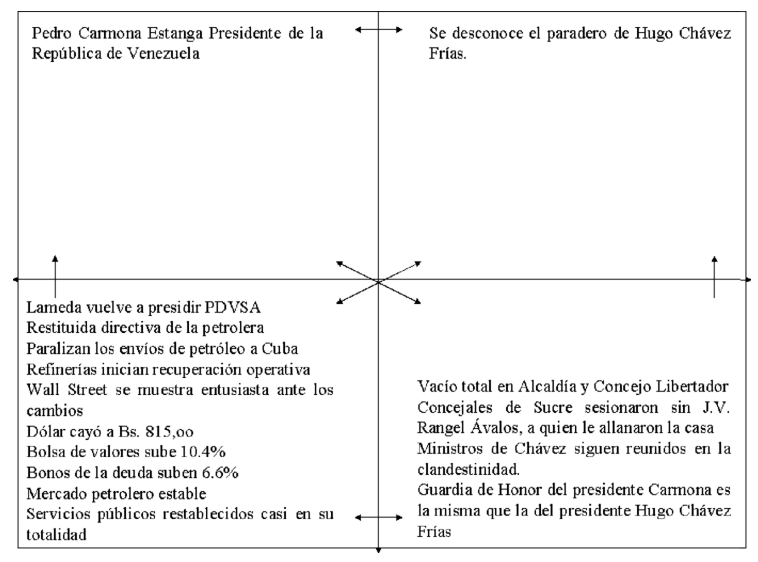

Análisis sobre la base del cuadrado semiótico del día 13 de abril: fase 2/3

Este es el cuadrado semiótico en que se retoman las posiciones isotópicas de la condición inicial.

Lo interesante de este cuadrado es que la agenda informativa internacional genera reacciones muy claras en contra de las decisiones adoptadas por el interinato de Carmona Estanga.

Figura $n^{\circ} 8.13$ de abril: 2/3 Aplicación del cuadrado semiótico de Greimas

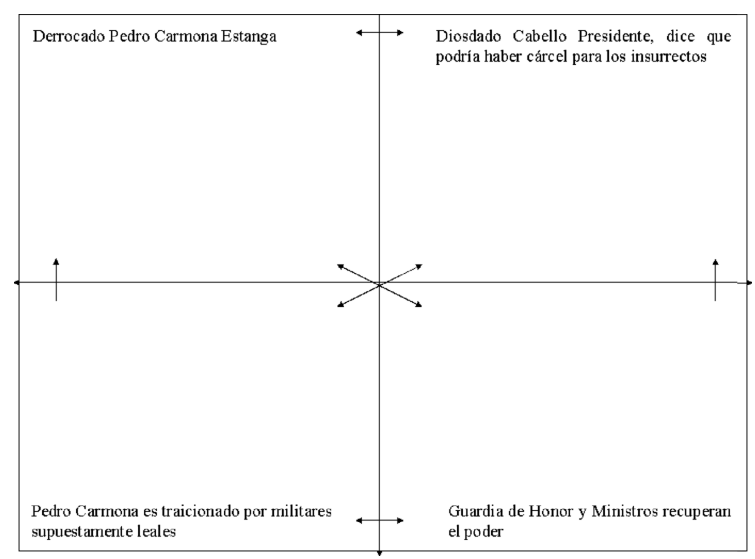

Análisis sobre la base del cuadrado semiótico del día 13 de abril: fase 3a/3. Se observa pérdida isotópica 
La pérdida del poder por parte de la oposición genera manifestaciones de tono violenta hacia los medios de comunicación social locales por parte de grupos afectos al chavismo. Esta condición genera un vacío informativo desde los medios de comunicación social venezolanos hacia el ámbito local, convirtiendo a los medios internacionales en los únicos responsables del manejo informativo de la realidad venezolana.

$\mathrm{Al}$ existir una confusión de roles por las manifestaciones, saqueos y disturbios, al dejar de tener la hegemonía informativa por parte de los medios nacionales, el vacío es llenado por las cadenas informativas internacionales, produciéndose, desde nuestro punto de vista, el Efecto CNN.

Figura $n^{\circ}$ 8. 13 de abril: 3a/3 Aplicación del cuadrado semiótico de Greimas. Se observa pérdida isotópica

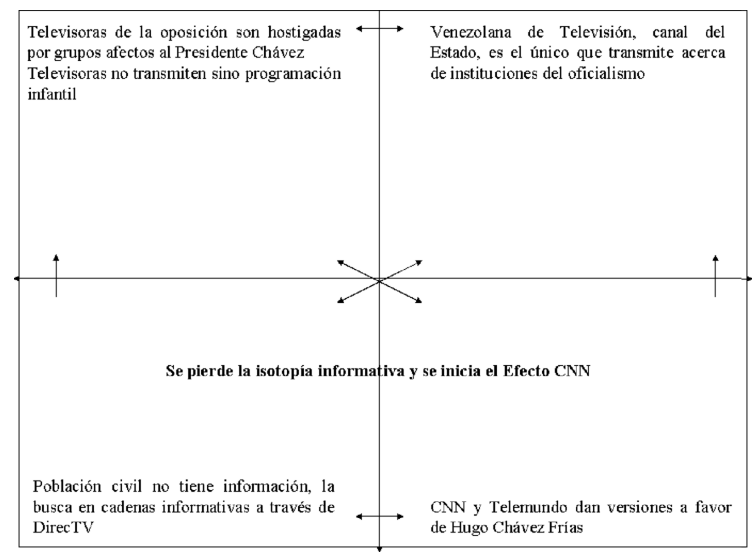

Análisis sobre la base del cuadrado semiótico del día 13 de abril: fase 3b/3. Sigue la pérdida isotópica.

Las revueltas civiles, incontrolables por parte de los órganos de seguridad del estado, son reflejadas a través de CNN y radio Caracol de Colombia, y son vistas por los venezolanos a través de DirecTV. Pasado un tiempo, con miras a dominar los empresarios de los medios de comunicación venezolanos el panorama político, se deja de transmitir a través del canal por suscripción información internacional, razón por la cual, las cadenas internacionales se convierten en la única fuente informativa que desde Venezuela, excluyendo al país, se tiene.

Esta coyuntura informativa genera verdadera confusión en la población venezolana. 
Figura n ${ }^{\circ}$ 9. 13 de abril: 3b/3 Aplicación del cuadrado semiótico de Greimas. Sigue la pérdida isotópica.

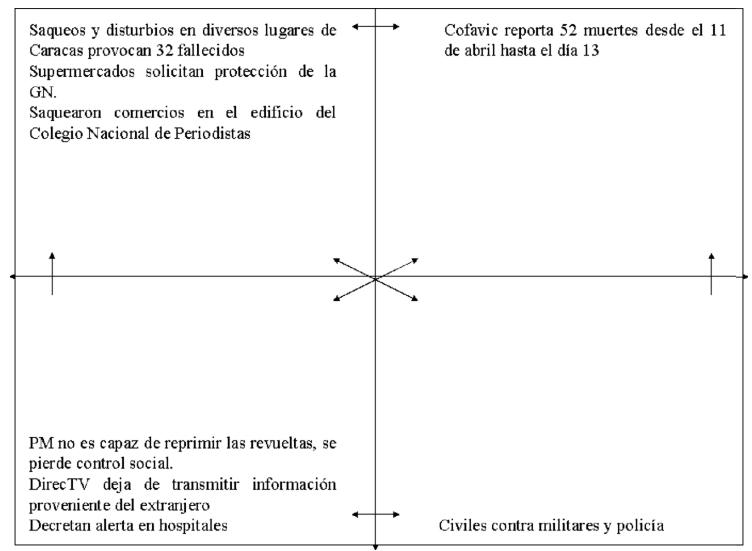

Análisis sobre la base del cuadrado semiótico del día 13 de abril: fase 3c/3. Sigue la pérdida isotópica.

No se conoce quien detenta el poder político ni quien informa.

Se mantiene el Efecto $C N N$, por ser las cadenas internacionales de noticias las que generan la información que desde Venezuela se conoce.

Figura $\mathrm{n}^{\circ}$ 10. 13 de abril: 3c/3 Aplicación del cuadrado semiótico de Greimas. Sigue la pérdida isotópica.

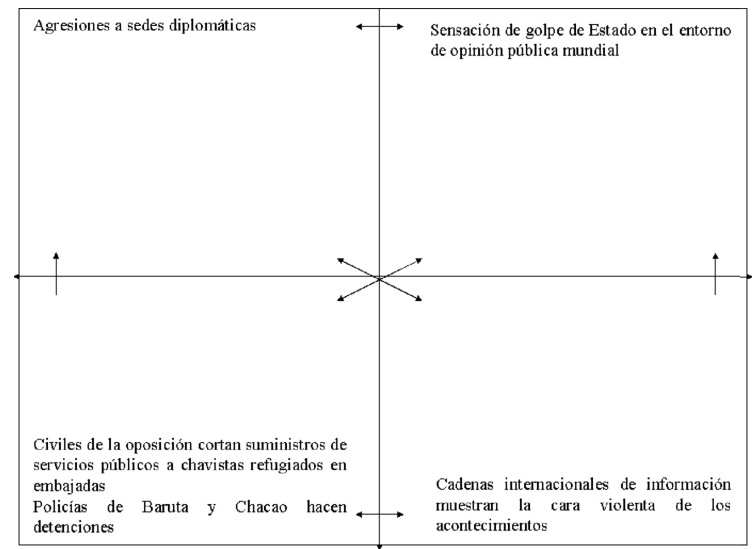

Análisis sobre la base del cuadrado semiótico del día 13 de abril: fase 3d/3. Sigue la pérdida isotópica 
Al retomarse el poder político, al tener claridad institucional, al tener los actores sociales un panorama claro de los acontecimientos, los órganos de seguridad del Estado retoman el control, los medios de comunicación social venezolanos vuelven a generar noticias desde y para el ámbito local, perdiéndose o finalizando el Efecto CNN.

Figura $n^{\circ}$ 10. 13 de abril: 3d/3 Aplicación del cuadrado semiótico de Greimas. Sigue la pérdida isotópica

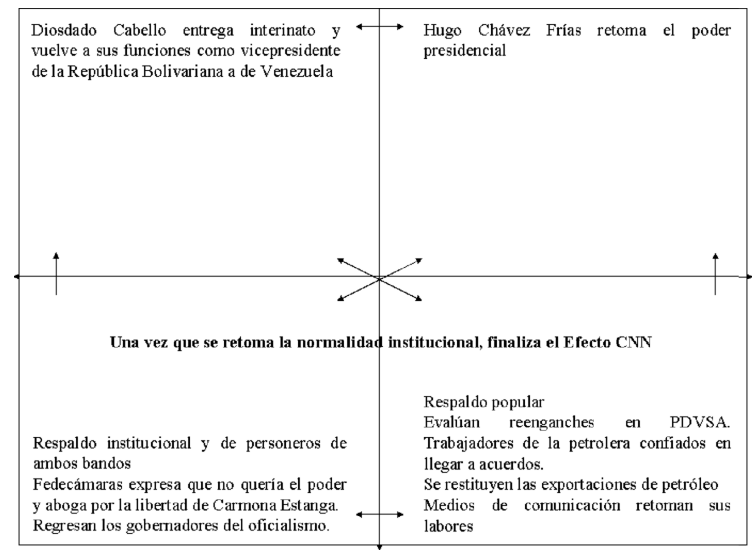

\section{Conclusiones}

Hemos llevado tres días de acontecimientos venezolanos a un ámbito semiótico. La expresión de cada una de las matrices, creemos dibuja las posibilidades y panorama que tuvo cada uno de los actores del conflicto: opositores y oficialistas. Podemos desentramar de cada uno de los paralexemas las relaciones, lealtades y traiciones que tuvo cada parte con instituciones y personas.

Este tiempo, que ha dado tanto de qué hablar en nuestro país, seguirá siendo parte del misterio de la historia contemporánea y no es función de este trabajo desentrañarlo.

Este trabajo no puede salirse de su ubicación espacio-temporal: los acontecimientos de abril de 2002.

Tampoco pretendió este trabajo analizar o ubicar. las posiciones o intenciones de los distintos actores de esos hechos, ni siquiera de las intenciones últimas de los medios de comunicación social implicados desde el extranjero (CNN), sino se fundó en analizar desde una mirada semiótica la irrupción del Efecto CNN que, en un plano de subjetividad interpretativa que vivimos los venezolanos en esos momentos, procura dar a 
comprender lo que realmente pasaba, y cómo los medios de comunicación social internacionales, pretendieron (saliéndonos del concepto greimasiano) informar para ese plano desinformado de la población.

Evidentemente, el discurso de esos días fue tal y como lo manifiesta Greimas heterogéneo, un todo de significación.

Consideramos, alcanzados los objetivos que nos hemos propuesto, como muy válido el concepto del Efecto CNN a la luz de los acontecimientos de abril de 2002 en Venezuela, toda vez que la soberanía mediática, en especial el día 13 de abril a nuestro juicio, se perdió y fue sustituida por una hegemonía de medios internacionales que informaban a los venezolanos desde el mismo lugar de los acontecimientos a través de cadenas internacionales.

Si observamos que durante los días de abril mencionados es en particular el día 13 en el que se desdibuja la relación lexémica que venimos destacando y, que es sobre esa base que surge el Efecto CNN, se nos plantea desde el punto de vista teórico de la semiótica un vacío en el plano greimasiano.

Una vez concluido el análisis que nos hemos propuesto, tenemos dos grandes grupos de conclusiones:

Desde el punto de vista semiótico:

- La propuesta greimasiana del estudio de los elementos textuales a través del cuadrado semiótico tiene el riesgo de la pérdida isotópica en temas de conflictividad social o política.

- El esquema greimasiano, si bien es muy útil para ciertos estudios discursivos, no es de valía para estudios en los que el ámbito cultural o coyuntural sea el relevante.

- Igualmente, en algunos casos la metodología greimasiana debe "acomodarse" para que los fenómenos sociales puedan tener cabida dentro del esquema semiótico del griego.

Desde el punto de vista del Efecto CNN:

- Si bien es cierto que este efecto no está demostrado fehacientemente, la aplicación de la metodología greimasiana nos ha permitido ver cómo es que se puede producir el llamado Efecto CNN.

- $\quad$ Por otra parte, es muy cierto que además de los actores involucrados, la agenda informativa de Venezuela durante los días 11 al 13 de abril podría haber desencadenado hacia cualquier desenlace. Mas la coyuntura informativa internacional fue determinante para el retorno del hilo constitucional. 


\section{RECOMENDACIONES}

- $\quad$ Desde el punto de vista semiótico: Es preferible, si se quiere usar un método semiótico de estudio para fenómenos sociales o políticos que se sigan corrientes de pensamiento más vinculadas a las propuestas peircianas.

- $\quad$ Desde el punto de vista del Efecto CNN: Habría que evaluar más fenómenos de tono informativo internacional para darle un verdadero sitial a este efecto hegemónico informativo.

\section{Referencias bibliográficas}

Bartley, K. y O'Briain, D. (2003): La Revolución no será televisada. Documental respaldado por BBC - Londres.

Centro de Medios Independientes de Puerto Rico (2005): El Efecto CNN: un instrumento de ilusión destinado a la opinión pública. [En línea]. Tomado el 07 de abril de 2006, de: http://pr.indymedía.org/print.php?id=8189).

El Universal (diario), primeras páginas de los días 12, 13 y 15 de abril. C.A. El Universal, Caracas.

Fontanille, J. (2001): Semiótica del discurso; Perú: Fondo de Cultura Económica.

Garrido, A. (2003): Notas sobre la revolución bolivariana, Venezuela: Producciones Karol.

Greimas, A.J. (1976): Semántica estructural, Madrid: Editorial Gredos:

La Fuente, S. y Meza, A. (2003): El acertijo de abril. Relato periodístico de la breve caída de Hugo Chávez, Caracas: Debate. Langa, A. (2006): La crisis de Darfur y el Efecto CNN. [En línea]. Tomado el 07 de abril de 2006, de http:/ /www.sector3.net/ portal11/art_crisisdarfur.asp

Machillanda, J. (2002): El 11-A la huída de Chávez, (comp.), Caracas: Paz y paz.

Martínez, I. (21 de abril, 2002): Crónica del último día [En línea]. publicado en El Nacional. Tomado el 13 de agosto de 2006, de: http://www.antiescualidos.com/pag/Anti/Portal/Secciones/Articulos/DOSSIERGOLPE/IBSEN.HTML.

Meysaan, T. (2005): El Efecto CNN. La desinformación espectáculo. [En línea]. Tomado el 04 de julio de 2006, de: http://www.voltairenet.org/article125917.html.

Nöth, W. (1995): Handbook of semiotics, United States of America: Indíana University Press.

Trejo, R. (2003): Sociedad y Poder. [En línea]. Tomado el 13 de septiembre de 2003, de: http://raultrejo.tripod.com/SociedadyPoder2003/gueraacnnmarzo25.htm.

Treviño, J. (2005): Efecto CNN [En línea]. Tomado el 07 de abril de 2006, de: http://javiertrevino.blogspot.com/2005/ 06/efecto-cnn-html 